\title{
OPEN REDUCTION AND INTERNAL RIGID FIXATION OF UNILATERAL DISPLACED SUBCONDYLAR FRACTURES USING A SINGLE TRAPEZOIDAL PLATE VERSUS THE TRADITIONAL TWO MINIPLATES. A COMPARATIVE STUDY
}

\author{
Essam M. Ashour*
}

\begin{abstract}
Purpose: The aim of this study was to compare clinically and radiographically between the single three-dimensional Trapezoidal plate versus the traditional two non-parallel miniplates in ORIF of unilateral displaced subcondylar fractures.

Patients and Methods: A total of 24 patients suffering from unilateral displaced subcondylar fractures were randomly divided into two equal groups; Group I patients were treated using single trapezoidal plates while Group II patients were treated using the traditional two miniplates. The clinical parameters include; the Hardware application time, maximum interincisal opening, Protrusive, ipsilateral and contralateral movements, mandibular mobility index, Helkimo index of mandibular dysfunction, facial nerve weakness and plate fracture. Radiographic parameters included: Vertical height of the ramus, anteroposterior and mediolateral condylar angulations. All the clinical and radiographic outcomes were assessed and statistically analysed preoperatively and at all post-operative follow-up intervals.
\end{abstract}

Results: Group I showed a statistically significant lower hardware fixation time in comparison to Group II.Both groups showed no significant difference regarding MMO, protrusive, ipsilateral and contralateral movements. Moreover, the difference regarding vertical ramus height, anteroposterior, and mediolateral condyle angulations was statistically insignificant. Two patients of group II had Plate fracture at the 1-month follow-up interval. Transient weakness of the frontal branch of the facial nerve was observed immediately post-operatively in two patients of group II and recovered completely within 3 months.

Conclusion: The results of the present study support the superiority of the single Trapezoidal plates in ORIF of displaced subcondylar fractures with special recommendation for high subcondylar fractures.

KEYWORDS: Subcondylar fractures, Trapezoidal and miniplates plates, vertical ramus height, condylar angulation

\footnotetext{
* Associate Professor of Oral and Maxillofacial Surgery, Faculty of Dentistry, October 6 University, Egypt.
} 


\section{INTRODUCTION}

Mandibular fractures are considered one of the most common and predominant maxillofacial injuries since the mandible being considered the second most displayed area of the face after the nasal bones. As the condylar neck represents the thinnest part of the mandibular skeleton, it is considered the etiologic factor responsible for the high incidence of condylar fractures. ${ }^{(1-4)}$ These fractures constitute about $12-16 \%$ of all facial fractures and $30-40 \%$ of mandibular fractures. ${ }^{(4-6)}$

Management of Condylar fractures is often subjected to discussion and controversy among maxillofacial topics and accordingly, different treatment modalities had been suggested in the literature. (7) The controversy was related to the continuous debate regarding closed conservative management versus open surgical management of condylar and subcondylar fractures. ${ }^{\left({ }^{8}\right)}$

Those who approve and advocate closed conservative treatment dispute that post-surgical morbidity exceeds and overweighs the post-surgical outcomes, and a short period of maxillomandibular fixation followed by aggressive mouth opening physiotherapy exercises are sufficient to achieve adequate occlusion and mandibular mobility through a non-invasive and less aggressive treatment modality. ${ }^{(9,10)}$

On the other hand, those who favour open surgical treatment debate that only open reduction and internal rigid fixation can prohibit and hinder the occurrence of various sequalae and complications of the closed treatment modality presented as inadequate restoration of the reduced vertical ramus height, facial asymmetry, restriction of mandibular movements, muscle spasms, mandibular deviation on opening, malocclusion, ankylosis and pathologic alterations of the temporomandibular joint. Open surgical treatment, accordingly, favours immediate functional jaw movements in a short recovery period. ${ }^{(7,8,11-13)}$ These forementioned advantages have deemed ORIF a favourite among maxillofacial surgeons.

The generally accepted and intended objectives of open reduction and internal rigid fixation (ORIF) of subcondylar fractures is restoration of adequate anatomical repositioning and consequently permitting immediate functional jaw movements. Any hardware fixation system should ideally be able to tolerate and counteract the compressive and tensile forces subjected to the condylar area. Titanium plates and screws of various designs and configurations had been extensively used for the purpose of rigid fixation of subcondylar fractures. ${ }^{(14)}$

Traditionally. the two non-parallel mini-plates fixation system applied according to Champey's technique had been advocated by many surgeons for successful fixation of subcondylar fractures as they had provided adequate anatomical repositioning with fixation stability and rigidity and minimal postoperative complications. ${ }^{(6,14,15)}$

Meyer et al. ${ }^{(16)}$ was the first who introduced and advocated the use of the trapezoidal plates for the purpose of fixation of subcondylar fractures. In their experimental study, the trapezoidal plate yielded satisfactory outcomes regarding its ability to provide adequate rigidity for subcondylar fractures fixation. ${ }^{(16)}$ Trapezoidal plates have also been used successfully in adult populations and proved to provide adequately stable subcondylar fracture fixation. ${ }^{(11,17,18)}$

The biomechanical performance of different plating systems and designs had been compared in various invitro finite element analyses that reported the superiority of trapezoidal plates in fixation of subcondylar fractures. ${ }^{(19,20)}$ It has been postulated that both plating systems whether the single trapezoidal plate or the two miniplates favoured a stable rigid subcondylar fracture fixation when applied along the anterior and posterior tension and compression condylar zones. 
In both experimental and clinical studies, shortening of the vertical ramus height of the fractured condyle and the degree of condylar fragment displacement were considered of paramount importance as reference indicators. ${ }^{(21)}$ The objectives of successful treatment of condylar and subcondylar fractures are adequate reduction of the displaced condylar fragment with appropriate and sufficient restoration of the reduced vertical ramus height and condylar angulations. Post-operative maintenance of these objectives and reference indicators are of paramount importance regarding mandibular mobility, occlusion and TMJ function. ${ }^{(22)}$

This reported clinical study was designed to compare clinically and radiographically between the single three-dimensional Trapezoidal plate versus the traditional two non-parallel straight miniplates in the reduction and fixation of unilateral displaced subcondylar fractures regarding the vertical ramus height and antero-posterior and medio-lateral condylar angulations and also to boost or confute the superiority of one plating system over the other.

\section{MATERIALS AND METHODS}

This prospective comparative clinical study was conducted from November 2016 to October 2020. A total of 24 patients who sustained unilateral displaced subcondylar mandibular fractures that were indicated for open reduction and internal rigid fixation (ORIF) were selected from the outpatient clinic of the oral and maxillofacial surgery department, Faculty of Dentistry, October 6 University.

Patients were randomly divided into two equal groups.

Group I (Study group): consisted of 12 patients where ORIF was achieved using single threedimensional Trapezoidal plates.

Group II (Control group): enrolled 12 patients where ORIF was achieved using two traditional non-parallel miniplates, one parallel to the posterior border of the mandible and the other parallel to the sigmoid notch or the anterior condylar border.

\section{A) Pre-operative Phase:}

Inclusion criteria: To be certified for surgery, patients were required to fulfil the following criteria: 1 . Medically fit patients free from systemic compromising diseases contraindicating surgery. 2. Patients ranging in age from 20 to 50 years old. 3. Patients suffering from unilateral displaced extracapsular subcondylar fractures indicated for ORIF requested treatment within one week from trauma.

Exclusion criteria: Patients were excluded from the study if they fulfil the following criteria: 1 . Patients with intracapsular condylar head fractures, bilateral or comminuted condylar fractures. 2 . Patients with associated maxillary or midfacial fractures. 2. Patients with debilitating systemic diseases, bone pathology or bone metabolic disorders.

Patients in this prospective comparative clinical study were assessed preoperatively according to the routine protocol of Oral and Maxillofacial Surgery thorough history taking with clinical and radiographic examinations.

Clinical examination; All patients enrolled in this study were clinically examined by inspection and palpation in order to assess the site and type of fracture as well as any associated mandibular fractures, the presence of edema, ecchymosis, soft tissue lacerations, step deformities, mobility of fractured segments, dentition status, maximal interincisal opening, derangement of occlusion, and temporomandibular joint associated symptoms.

Radiographic examination: A standard digital Orthopantomogramic view (O.P.G) was taken for each patient at the time of presentation for assessment of the site and type of the fracture line and detection of any associated dentoalveolar injuries of related 
teeth and presence of other associated fractures. Full skull Cone Beam Computed Tomography (CBCT) was taken for all patients preoperatively and at all postoperative follow-up intervals at 1 week and 1, 3 and 6 months. Reformatted panoramic and coronal views were obtained from the CBCT eliminating any magnifications produced by standard panoramic views.

The pre-operative digital O.P.G reformatted from the CBCT without any magnification (1:1) was used to assess the vertical ramus height and the anteroposterior angulation of both the unfractured and the fractured displaced condylar segment by measuring and recording the values preoperatively and at all postoperative radiographic followup intervals. The reformatted coronal view was also used to measure the medio-lateral condylar angulation preoperatively and at all postoperative radiographic follow-up intervals.

Before any definitive treatment, care of any lacerated soft tissues and wound debridement were performed for all patients presented with compound fractures. Teeth in fracture lines were managed according to preoperative assessment either by extraction or preservation. Intravenous antibiotics were administered preoperatively at the time of admission and were continued until discharge.

Full detailed written consents were signed by all patients explaining all steps of the surgical intervention and expected complications. Appropriate ethical clearance was obtained from the Faculty of Dentistry, October 6 University.

\section{B) Operative Phase:}

Patients were operated under general anaesthesia using endotracheal intubation, then the surgical site was disinfected and patients were draped in the usual manner.

Prior to open reduction, patients were placed into intermaxillary fixation (IMF) with the aid of arch bars or Ivy loops to achieve proper occlusion.
Exposure of any associated parasymphyseal, body or angle fractures was delt with first by intra and/or extra-oral mucosal or skin incisions followed by reduction and rigid fixation with 2 mini-plates at the compression and tension zones according to Champey's technique.

Exposure of the subcondylar fracture site was then entailed through a modified Retromandibular Retro-parotid approach about 2.5-3 cm long skin incision made $2 \mathrm{~cm}$ behind and parallel to the posterior mandibular border and $5 \mathrm{~mm}$ below the ear lope not extending beyond the mandibular angle. First, the incision was carried out through the skin and subcutaneous tissues, then sharp dissection was carried through the SMAS layer, followed by blunt dissection to separate the parotid gland and capsule from fibrous adhesions to the sternocleidomastoid muscle.

The parotid gland with its contents and associated facial nerve branches was then bluntly dissected and retracted antero-superiorly providing access to the posterior border of the mandibular ramus. A sharp incision was made along the periosteum of the posterior border of the mandibular ramus then the masseter muscle was reflected anteriorly through a subperiosteal dissection exposing the ramus up to the sigmoid notch and the subcondylar fracture site. The IMF was then released to allow inferior retraction of the mandibular ramus by application of a sigmoid or toe-out retractor, which revealed a sufficient working space for reduction of the fractured condylar segment. The fractured proximal condylar segment was localised and carefully dissected and freed from any adherent muscular or capsular soft tissue attachments then grasped by a Kocher and manipulated and reduced to its anatomical position against the ramal stump.

Fixation of the reduced condylar fragment in group I patients was achieved by using a single Trapezoidal 3D miniplate (Jeil Medical Corporation, Guro-gu, Seoul, Korea) secured by four $2.0 \mathrm{~mm}$ 
mini-screws 6-8 $\mathrm{mm}$ in length, while in group II patients, fixation was achieved by using two 2.0 $\mathrm{mm}$ straight miniplates (Jeil Medical Corporation, Guro-gu, Seoul, Korea) adapted and contoured so that one plate parallels the posterior mandibular border acting as the compression plate according to Champey's technique while the other parallels the sigmoid notch or the anterior condylar border acting as the tension plate. The posterior miniplate was secured by two screws on either side of the fracture line. The anterior miniplate was secured by one screw on either side of the fracture line in cases of high subcondylar fractures owing to the limited small available area on the proximal condylar segment while two screws were used on either side in cases of low subcondylar fractures. The 2 plates were secured by $2.0 \mathrm{~mm}$ mini-screws $6-8 \mathrm{~mm}$ in length. (Figure 1)
It has to be noted that in cases where it was impossible to attain adequate occlusion and satisfactory intercuspation owing to fracture segment telescoping and over-riding, surgical exposure and preliminary reduction of all fracture sites was executed first, after which occlusion could be adequately restored and IMF could be attained by arch bars or Ivy loops before application of the rigid fixation plates. Again, any associated fracture sites were reduced, plated and rigidly fixed first before dealing with the subcondylar fracture.

IMF was then released to check free unrestricted mandibular movements and confirm both the establishment of a repeatable centric occlusion and the stability of the plate fixation apparatus at the fracture site. The oral pack was then removed. Closure of the wound was done in layers using

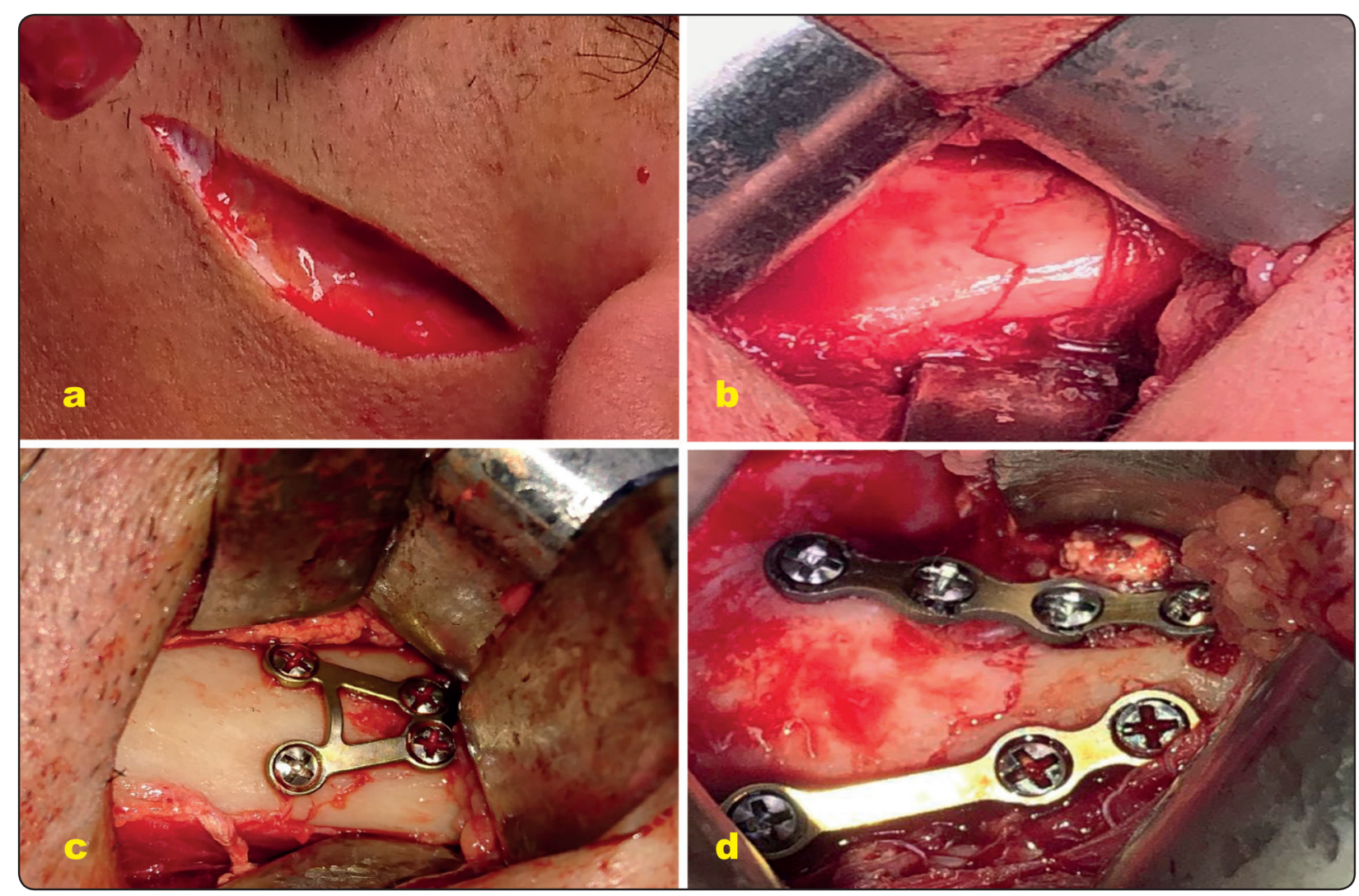

Fig. (1): Intra-operative photos showing a. Modified Retromandibular incision. b. Reduced subcondylar fracture. c. Single Trapezoidal plate fixing the proximal condylar fragment. d. Two compresion and tension miniplates fixing the proximal condylar fragment. 
3/0 polyglycolic polylactic sutures (Vicryl, Ethicon, Cornelia, GA, USA) for deep layers. The periosteum and the pterygo-masseteric sling were sutured as one layer followed by the SMAS and the Parotido-massteric fascia as a second layer and then the subcutaneous tissues as a third layer. Finally, the skin layer was closed using 5/0 subcuticular polypropylene sutures (Prolene, Ethicon, Cornelia, GA, USA).

\section{C) Postoperative Phase}

Surgical compression dressings were placed to prevent hematoma formation for approximately 36 hours. Analgesics, anti-inflammatory drugs, antibiotics, and antiseptic mouthwashes were prescribed for 5 days postoperatively. Skin sutures were removed 1 week postoperatively and joint function was checked.

Patient were guided to receive soft and semifluid diet for 2 weeks with gradually increasing its consistency over the next weeks and instructed to begin mouth opening physiotherapy exercises by the third postoperative week.

\section{D) Follow-up Phase}

Clinical follow-up for all patients were scheduled at 1 week and 1,3, and 6 months post-operatively.

\section{Post-operative Clinical assessment}

Hardware application time; was measured from the start of fixation of the reduced condylar segment including plate bending and adaptation time till the last screw to be secured (finalization of osteosynthesis) using the stopwatch of the same digital clock for all patients.

Maximum Mouth opening; was assessed by measuring the distance in millimetres between the incisal edges of upper and lower incisors by a polygauge during maximal unassisted mouth opening.

Protrusive, ipsilateral and contralateral movements were assessed by measuring the distance in mms between the upper and lower dental midlines at protrusive and lateral movements.

Occlusion; Postoperatively, all patients were assessed for maximum intercuspal position and interdigitation to assure the midline centralization and the proper occlusal relationship including molar relation. Any occlusion disturbance, premature contact or open bite was considered as a malocclusion and was recorded for each group. Any complication was then treated by application of arch bars and heavy guiding elastics for 2-3 weeks.

Mandibular mobility index: Mandibular movements in all three planes were assessed according to Helkimo index. ${ }^{(23)}$

Temporomandibular disturbances; The joint function including any TMJ disturbances as tenderness, clicking or derangement was assessed according to Helkimo index. ${ }^{(23)}$

Plate fracture and screw loosening; was recorded radiographically and confirmed clinically by derangement of occlusion, mandibular mobility and surgical site infection.

\section{Post-operative Radiographic assessment}

Radiographic follow-up for all patients were scheduled pre-operatively and at 1 week and 1,3 and 6 months post-operatively initially to check proper reduction and detect any complications of non-union, plate fracture, or screw loosening of any plating system.

Radiographic assessment was carried out using CBCT with reformatted digital panoramic as well as coronal views in order to assess the Vertical ramus height, antero-posterior and medio-lateral condylar angulations.

\section{CBCT and image analysis protocols}

All the CBCT images were produced with the same device (Soredex-CRANEX 3D-Real PanCMOS sensor-Eng, USA) All obtained images were converted into Dicom files. Vistadent 3D 
2.0 software (GAC Dentsply, New York, NY, USA) was used to implement all recordings. The tomographic analysis was made in correspondence with the protocol previously instituted by Gribel et al. (24) who stated that measurements derived from the CBCT scans were appropriately more accurate for craniofacial analysis than traditional panoramic views which gives undefined and indistinct magnification of the true mandible.

Since the patient's head position during acquisition of CBCT images may vary during every radiographic examination at the different follow-up intervals, therefore the tool "set natural head position" was used. ${ }^{(25,26)}$

The radiographic points for determining the linear and angular measurements were identified by a single trained examiner. Following this, the linear and angular measurements were spontaneously calibrated by the software.

Vertical height of the ramus and antero-posterior angulation of the fractured condyle was measured using reformatted panoramic view of CBCT without magnification $(1 \mathrm{x} 1)$ where the reference points and landmarks were positioned according to the measurements proposed by Silvennoinen et al. (27) and compared to the measurements of the nonfractured contralateral condyle pre-operatively and at all post-operative radiographic follow-up intervals (figure 2,3).

\section{Vertical height of the ramus}

Ramal height was the distance between the mandibular line (ML: Tangent to the lower border of the mandible) and a tangent to the superior point of the condyle (CA) measured along the ramus line (RL: Tangent to posterior border of mandibular ramus excluding the condyle) on the fractured and nonfractured sides (from point $\mathbf{A}$ to point $\mathbf{D}$ ). Point $\mathrm{D}$ is the intersection between the ML and RL lines. (Table 1, Figures 2,3) Reduction of ramus height was represented by the difference in length between the fractured and nonfractured sides (AD-nf to AD-f).
For both groups, these measurements were recorded pre-operatively and compared to those of all post-operative radiographic follow-up intervals.

\section{Antero-posterior angulation}

Angulation between the proximal and distal fragments in the anteroposterior direction was calculated by measuring the $\mathrm{ABC}$ angle as shown in Figures 2 and 3. The ABC angle was measured between the ramus line (RL: Tangent to posterior border of the mandibular ramus excluding the condyle) and the posterior condylar line (CL: Tangent to the posterior border of condylar process). Angulation of the fractured side was considered to be the difference in degrees between the fractured and nonfractured

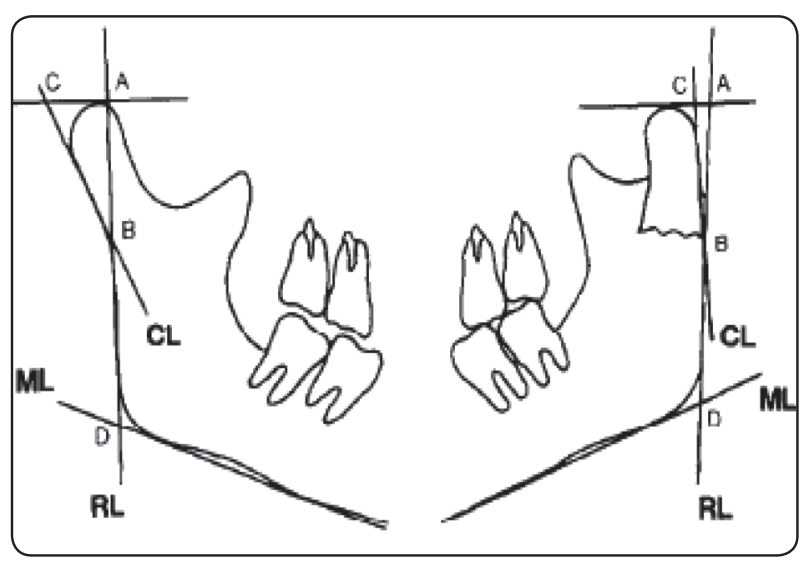

Fig. (2) : Diagram representing measurement of the vertical ramus height and antero-posterior condylar angulation as proposed by Silvennoinen et al. ${ }^{(27)}$

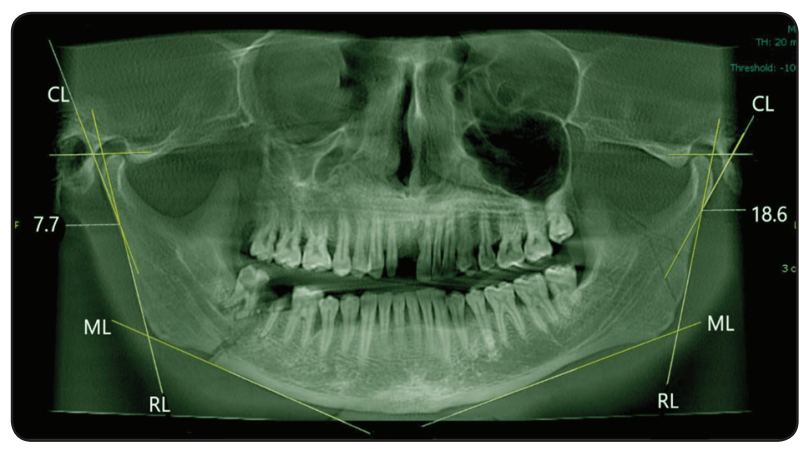

Fig. (3): Photograph of CBCT reformatted Digital Panoramic view demonstrating measurement of the vertical ramus height and Antero-posterior angulation of the mandibular condyle for the fractured and Unfractured condyles. 
TABLE (1) Landmarks and reference planes to measure vertical ramus height and Antero-posterior angulation of the mandibular condyle.

\begin{tabular}{|l|l|}
\hline \multicolumn{1}{|c|}{ Land mark } & \multicolumn{1}{c|}{ Description } \\
\hline Point (A) & Most superior point of the head of the mandibular condyle \\
\hline Ramal Line (RL) & $\begin{array}{l}\text { A tangential line of the posterior ramus connecting the points with greatest convexity on } \\
\text { the posterior border of the mandibular ramus excluding the condyle. }\end{array}$ \\
\hline Mandibular Line (ML) & $\begin{array}{l}\text { A tangential line of the lower border of the mandibular body [a tangent through the two } \\
\text { points of greatest convexity on the inferior border of the mandible }\end{array}$ \\
\hline Condylar Line (CL) & A tangential line to the posterior border of condylar process. \\
\hline CA line (CA) & A tangential line to the most superior point of the head of the mandibular condyle. \\
\hline Point (D) & The intersection between the ML and RL lines. \\
\hline $\begin{array}{l}\text { Antero-Posterior condylar angulation of } \\
\text { the fractured condyle (ABC - f angle) }\end{array}$ & The angle between the RL and CL lines of the fractured condyle. \\
\hline $\begin{array}{l}\text { Antero-Posterior condylar angulation of } \\
\text { the unfractured condyle (ABC - nf angle) }\end{array}$ & The angle between the RL and CL lines of the unfractured condyle. \\
\hline $\begin{array}{l}\text { Vertical ramus height at the fractured } \\
\text { side (AD -f) }\end{array}$ & The distance between the ML and CA measured along the RL line at the fractured side. \\
\hline $\begin{array}{l}\text { Vertical ramus height at the } \\
\text { unfractured side (AD - nf) }\end{array}$ & The distance between the ML and CA measured along the RL line at the unfractured side. \\
\hline
\end{tabular}

sides. (Table 1, Figures 2,3) For both groups, these measurements were recorded pre-operatively and compared to those of all post-operative radiographic follow-up intervals.

\section{Medio-lateral angulation in coronal CBCT view}

The displacement in angulation was defined as the angle between the two midline axes of the condylar fragment and the stump of the ramus. We measured the angle directly on coronal CBCT

TABLE (2) Landmarks and reference planes to measure the Medio-lateral angulation of the fractured condyle in coronal CBCT view.

\begin{tabular}{|l|l|}
\hline Landmark & \multicolumn{1}{|c|}{ Description } \\
\hline RML & Midline axis of the ramus stump \\
\hline CML & Midline axis of the condylar stump \\
\hline RC-f & M-L Angle of fractured condyle \\
\hline RC-nf & M-L Angle of unfractured condyle \\
\hline
\end{tabular}

images according to Changa et al ${ }^{(26)}$ and Neff et al (27) and the degree of angulation was the difference between the angles of the fractured and unfractured condyles. (Table 2, Fig 4) For both groups, these measurements were recorded pre-operatively and compared to those of all post-operative radiographic follow-up intervals.

\section{Statistical analysis}

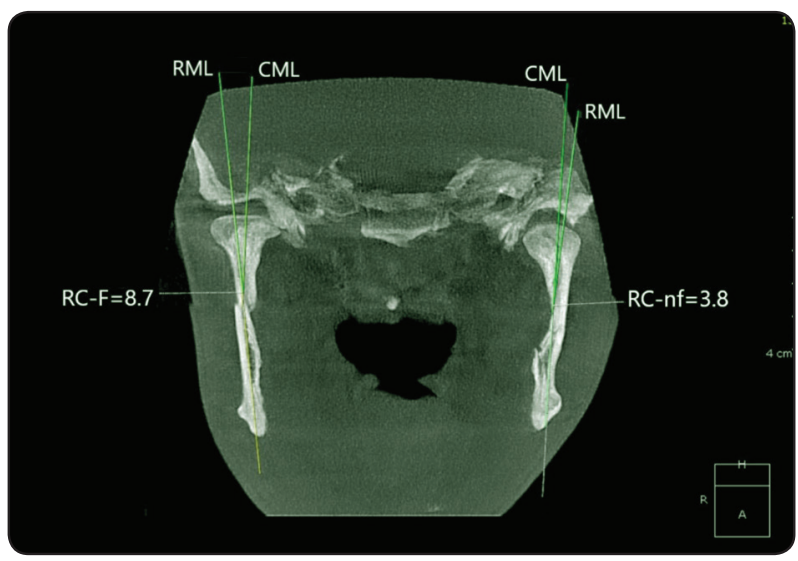

Fig. (4): Photograph of Preoperative Coronal view of CBCT demonstrating measurement of the Medio-lateral angulation of the fractured and unfractured condyles. 
Normally distributed quantitative data were presented as mean, standard deviation and range. Paired $t$ test was used to compare values of subsequent observation times. Independent $t$ test was used for intergroup (between groups) comparison. Qualitative data were expressed as number and percentage and were compared between groups and within different observations of the same group using chi square test. The significance level was set at $\mathrm{p} \leq 0.05$. Statistical analysis was then performed using a commercially available software program (SPSS 18; SPSS, Chicago, IL, USA).

\section{RESULTS}

The present study enrolled 24 patients that were randomly divided into 2 equal groups and all their principal data were analysed and statistically compared. Baseline characteristics (Table 3) including age, sex distribution, aetiology of the trauma, side of the fracture, associated fractures

TABLE (3) Comparison of Base line characteristics between the two groups

\begin{tabular}{|c|c|c|c|c|}
\hline Variables & $\begin{array}{l}\text { Group I } \\
\text { (Single Trapezoidal } \\
\text { Plate) }\end{array}$ & $\begin{array}{c}\text { Group II } \\
\text { (Two Mini Plates) }\end{array}$ & $\begin{array}{c}\text { t or } X^{2} \\
\text { test }\end{array}$ & P value \\
\hline Age (years), mean \pm SD & $29.6 \pm 3.7$ & $31.2 \pm 2.5$ & 1.24 & $0.227 \mathrm{~ns}$ \\
\hline $\begin{array}{l}\text { Sex } \\
\text { Male } \\
\text { Female }\end{array}$ & $\begin{array}{c}11(91.6 \%) \\
1(8.3 \%)\end{array}$ & $\begin{array}{l}9(75 \%) \\
3(25 \%)\end{array}$ & & $0.672 \mathrm{~ns}$ \\
\hline $\begin{array}{l}\text { Aetiology of trauma } \\
\text { RTA } \\
\text { Fall } \\
\text { Assaults } \\
\text { Sports }\end{array}$ & $\begin{array}{c}8(66.6 \%) \\
2(16.6 \%) \\
2(16.6 \%) \\
0\end{array}$ & $\begin{array}{c}7(58.3 \%) \\
3(25 \%) \\
1(8.3 \%) \\
1(8.3 \%)\end{array}$ & 1.6 & $0.659 \mathrm{~ns}$ \\
\hline $\begin{array}{l}\text { Side of fracture } \\
\text { Right } \\
\text { Left }\end{array}$ & $\begin{array}{l}7(58.3 \%) \\
5(41.6 \%) \\
\end{array}$ & $\begin{array}{l}6(50 \%) \\
6(50 \%) \\
\end{array}$ & 0.168 & $0.682 \mathrm{~ns}$ \\
\hline $\begin{array}{l}\text { Association with other fractures } \\
\text { Isolated subcondylar fracture }\end{array}$ & $\begin{array}{l}9(75 \%) \\
3(25 \%)\end{array}$ & $\begin{array}{l}10(83.3 \%) \\
2(16.6 \%)\end{array}$ & 0.253 & $0.614 \mathrm{~ns}$ \\
\hline $\begin{array}{l}\text { Preoperative condylar displacement ( } \mathrm{n}=12 \text { fractures) } \\
\text { Medially displaced } \\
\text { Laterally displaced }\end{array}$ & $\begin{array}{l}4(33.3 \%) \\
8(66.6 \%)\end{array}$ & $\begin{array}{l}5(41.6 \%) \\
7(58.3 \%)\end{array}$ & 0.178 & $.673 \mathrm{~ns}$ \\
\hline Preoperative measurements MMO $(\mathrm{mm})$, Mean \pm SD & $23.50 \pm 5.78$ & $24.08 \pm 5.70$ & .249 & $.806 \mathrm{~ns}$ \\
\hline Protrusion Mean \pm SD & $2.84 \pm 0.42$ & $2.89 \pm 0.55$ & .251 & $.805 \mathrm{~ns}$ \\
\hline Ipsilateral movement Mean \pm SD & $5.15 \pm 0.67$ & $5.08 \pm 0.87$ & .211 & $.835 \mathrm{~ns}$ \\
\hline Contralateral movement Mean \pm SD & $3.15 \pm 0.64$ & $2.96 \pm 0.65$ & .728 & $.475 \mathrm{~ns}$ \\
\hline $\begin{array}{l}\text { Preoperative occlusion derangement } \\
\text { Absent } \\
\text { Present }\end{array}$ & $\begin{array}{c}1(8.3 \%) \\
11(91.7 \%)\end{array}$ & $\begin{array}{l}2(16.6 \%) \\
10(83.3 \%)\end{array}$ & 0.381 & $0.537 \mathrm{~ns}$ \\
\hline $\begin{array}{l}\text { Preoperative facial nerve weakness } \\
\text { Absent } \\
\text { Present }\end{array}$ & $\begin{array}{c}12(100 \%) \\
0(0 \%)\end{array}$ & $\begin{array}{c}12(100 \%) \\
0(0 \%)\end{array}$ & 0 & $1 \mathrm{~ns}$ \\
\hline
\end{tabular}

SD; standard deviation, RTA; road traffic accident, MMO; maximum mouth opening.

$X^{2}$ or Fisher's exact test for qualitative values and independent t test for quantitative values. 
of the mandible, condylar displacement, MMO, protrusive, ipsilateral, and contralateral mandibular movements, occlusion status and facial nerve weakness were comparable in the two groups with statistically insignificant difference between them (all $\mathrm{P}>0.05$ ).

All patients exhibited unilateral displaced subcondylar fractures. In group I, five patients had high subcondylar fractures while seven patients had low subcondylar fractures. In group II, four patients had high subcondylar fractures while eight patients had low subcondylar fractures.

Immediately post-operatively, Satisfactory occlusion had been achieved in all patients. Two patients (16.6\%) of group II (two miniplates) sustained Plate fracture at the 1-month follow-up. Occlusion was disturbed and heavy elastics were applied. These patients exhibited severe mandibular dysfunction and severely impaired mandibular mobility by the end of 6 months. However, none of the patients warranted a second surgery as they were satisfied from the overall results. In contrast, no patient in group I (trapezoidal plate) had sustained any plate fracture. However, plate fracture in both groups was statistically insignificant $(\mathrm{P}=0.119)$.

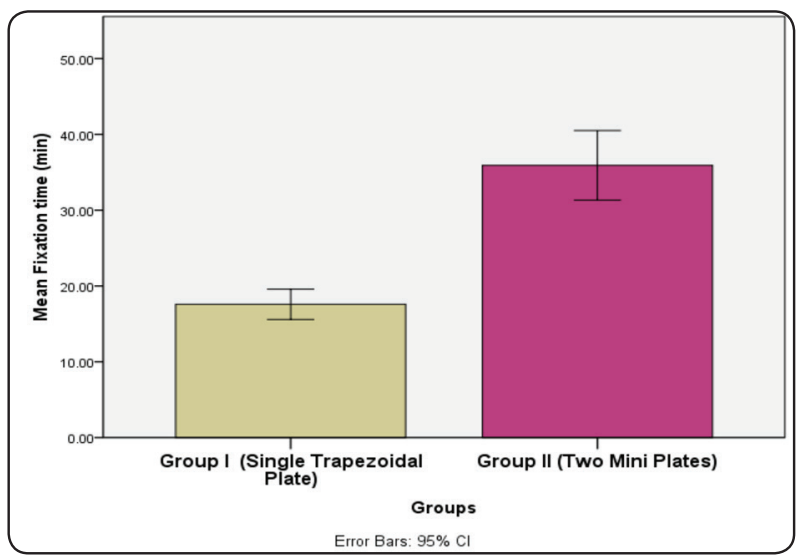

Fig. (5) Bar chart illustrating mean Plate fixation time (min) in both groups

\section{Hardware fixation time}

The median time taken for fixation of the Single Trapezoidal Plate in group I patients was $17.58 \pm 3.15$ minutes (ranging from 12-22 minutes) in comparison to group II (two miniplates), where the median time taken for fixation of the miniplates was 35.9 \pm 7.22 minutes (ranging from 23-46 minutes). (Fig 5) The difference was statistically significant $(\mathrm{P}=0.0001)$.

\section{Maximal Mouth Opening}

Immediately postoperatively, the range of MMO decreased in both groups, but gradually and significantly increased in both groups throughout all the follow-up intervals. The difference between the two groups was statistically insignificant. A normal range of mandibular movement was achieved in both groups within 6 months of follow-up. (Mean $42.50 \pm 1.00 \mathrm{~mm}$ for group I and $41.83 \pm 2.12 \mathrm{~mm}$ for group II). (Fig 6)

\section{Ipsilateral, contralateral and protrusive man- dibular movements}

Pre-operatively, the difference between both groups was statistically insignificant. Postoperatively, both groups showed a gradual increase in ipsilateral, contralateral and protrusive movements with no statistically significant difference between both groups in all follow-up intervals (Fig 7,8,9)

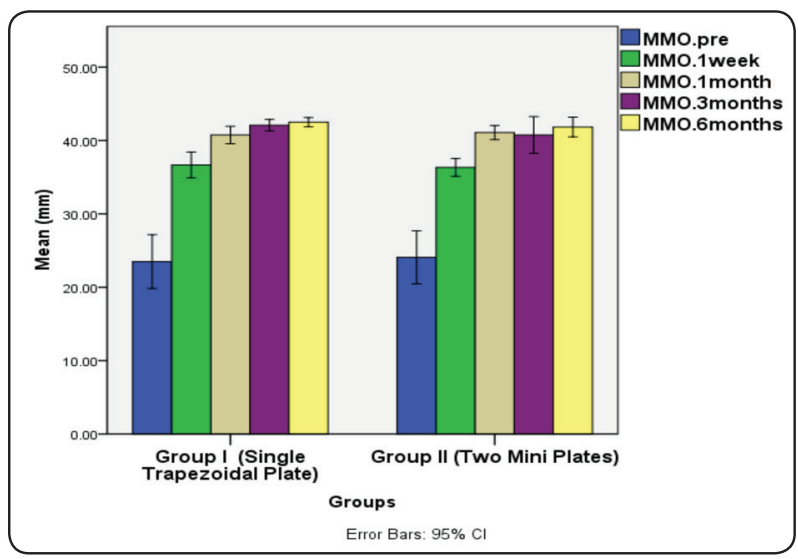

Fig. (6) Bar chart illustrating change in MMO in all follow-up periods 


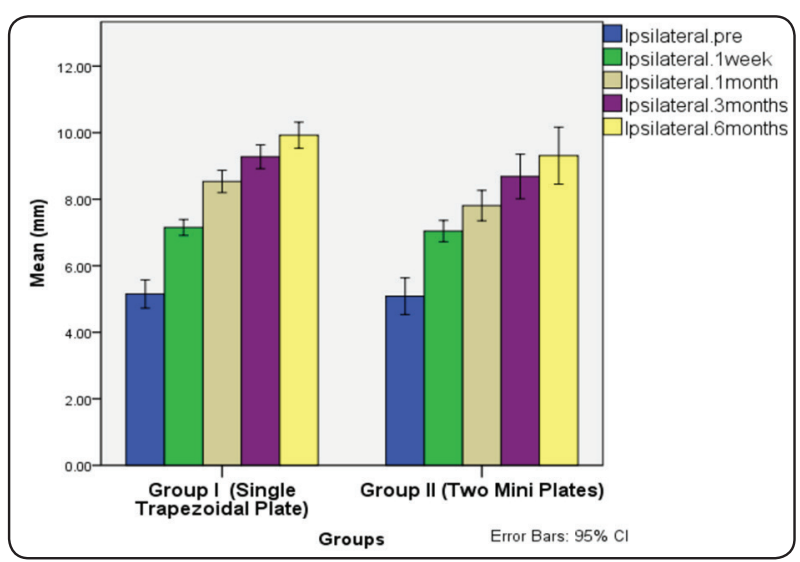

Fig. (7) Bar chart illustrating change in ipsilateral movements in all follow-up periods

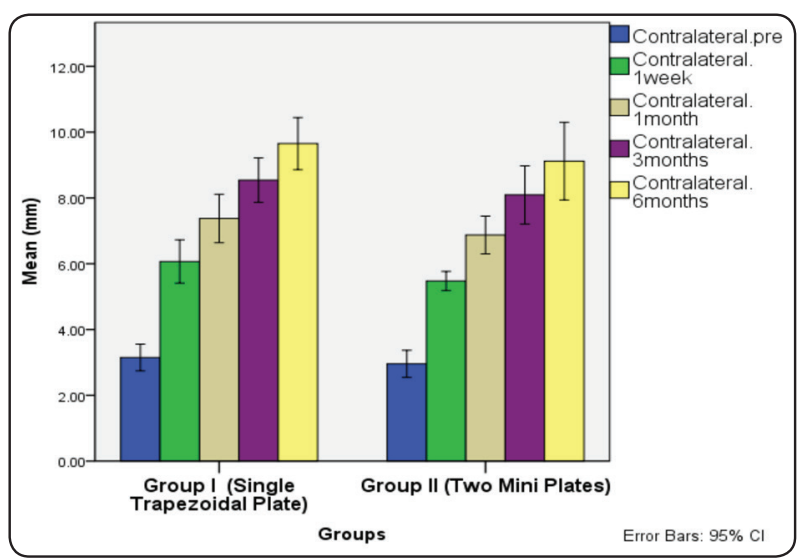

Fig. (8) Bar chart illustrating change in contralateral movements in all follow-up periods

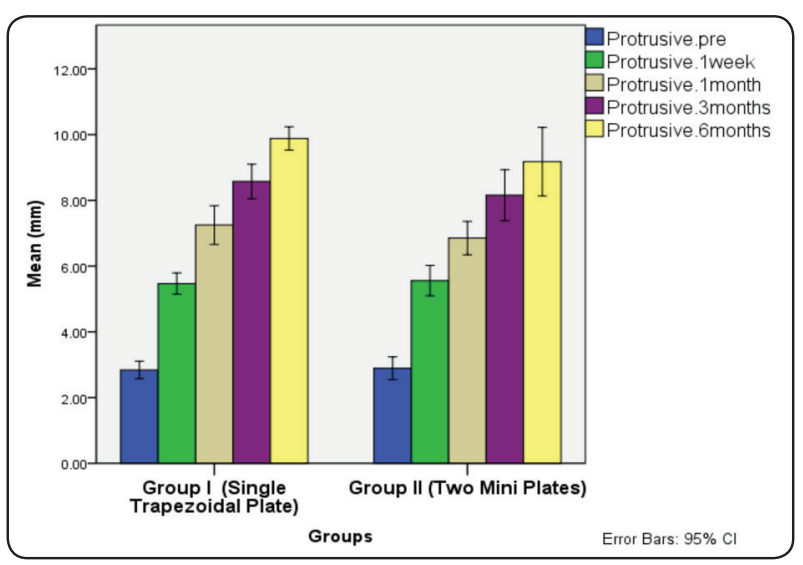

Fig. (9) Bar chart illustrating change in protrusive mandibular movements in all follow-up periods.
At the end of follow-up intervals, the maximum ipsilateral mandibular movements were between 6.5 to $10.6 \mathrm{~mm}$ with a mean of $9.93 \pm 62 \mathrm{~mm}$ for group I and between 6.3 to $10.5 \mathrm{~mm}$ with a mean of $9.31 \pm 1.35 \mathrm{~mm}$ for group II.

At the end of follow-up intervals, the maximum contralateral mandibular movements were between 7.4 to $10.8 \mathrm{~mm}$ with a mean of $9.95 \pm 1.25 \mathrm{~mm}$ for group I and between 6.3 to $11 \mathrm{~mm}$ with a mean of $9.37 \pm 1.86 \mathrm{~mm}$ for group II.

At the end of follow-up intervals, the maximum protrusive mandibular movements were between 4.5 to $10.6 \mathrm{~mm}$ with a mean of $9.88 \pm 56 \mathrm{~mm}$ for group I and between 3.5 to $10.4 \mathrm{~mm}$ with a mean of $9.18 \pm 1.64 \mathrm{~mm}$ for group II.

\section{Mandibular mobility index}

Pre-operatively, the difference between both groups was statistically insignificant. Postoperatively, both groups reported a gradual increase in mandibular mobility. At the 6 months follow-up interval, Mandibular mobility index showed that 10 patients (83.3\%) of group I were classified as E0 (normal mandibular mobility) and only 2 patients (16.6\%) were E1 (slightly impaired mobility) In contrast, 9 patients (75\%) of group II were classified as E0, one as E1 and 2 patients were classified as E2 (severely impaired mobility) (16.6\%). However, this difference was statistically insignificant $(\mathrm{P}=0.303)$.

\section{The Helkimo Index of mandibular dysfunction}

Pre-operatively, the difference between both groups was statistically insignificant. Postoperatively, both groups displayed a gradual improvement of mandibular function. At the 6 months follow-up interval, the Helkimo Index of mandibular dysfunction showed that 10 patients in group I were classified as D0 (free of symptoms) and 2 patients were classified as D1 (slight symptoms) whereas two patients $(16.6 \%)$ in group 
II developed severe mandibular dysfunction and classified as DIII and 2 patients were classified as DII (moderate dysfunction) at the end of follow-up intervals. However, this difference was statistically insignificant $(\mathrm{P}=0.528)$.

\section{Facial nerve weakness}

Immediately postoperatively, none of the group I patients had experienced facial nerve weakness, while two patients in group II developed weakness of the frontal branch of the facial nerve; however, this difference was statistically insignificant $(\mathrm{P}=$ $0.148)$. This reported facial nerve weakness was evident at the first post-operative day and had recovered completely by the third postoperative month. At 3 and 6 months, nerve weakness was absent in all cases of both groups.

\section{Radiographic evaluation}

Regarding the VRH, both groups showed statistically significant increase in VRH of the fractured condyle from pre-operatively to 1 -week $(\mathrm{p}=0.00)$ and insignificant increase from 1 -week to 1-month with no difference at 3 and 6 months. $(\mathrm{p}=1)$. (Fig 10)

The average postoperative shortening of the ascending ramus height compared to the unfractured side ranged from 0.4 to 1.5 in group I and from 0.2 to $1.6 \mathrm{~mm}$ in group II as shown in (Table 4) with statistically insignificant difference between both groups.

Regarding the Antero-posterior condylar angulation, both groups showed statistically significant decrease from pre-operatively to 1 -week and insignificant decrease from 1-week to 1-month with no difference at 3 and 6 months. (Fig 10)

The average degree of postoperative anteroposterior condylar displacement in group I was between 1.1 and 4.1 with a mean of $2.39 \pm .95$, while in group II, the degree of displacement was between
1.2 and 9.3 with a mean of $3.89 \pm 2.39$ (Table 5). Group I demonstrated greater decrease in condylar angulation compared to group II although the difference was statistically insignificant.

Regarding the Medio-lateral condylar angulation, both groups showed statistically significant decrease from pre-operatively to 1-week and insignificant decrease from 1-week to 1-month. In the interval from 1 month to 6 months both groups showed no significant difference in mediolateral condylar angulation ( $\mathrm{p}=1, \mathrm{p}=0.34$ respectively). (Fig 11)

The average degree of postoperative Mediolateral condylar displacement in group I was between 1.2 and 4.5 with aa mean of $3.34 \pm .97$, while in group II, the degree of displacement was between 1.2 and 7.6 with a mean of $4.13 \pm 1.79$ (Table 6). Group I demonstrated greater decrease in condylar angulation compared to group II although the difference was statistically insignificant.

\section{Comparison of results at the end of 6 months}

The median time taken for fixation of the Single Trapezoidal Plate in group I patients was $17.58 \pm 3.15$ minutes (ranging from 12-22 minutes) in comparison to group II (two miniplates), where the median time taken for fixation of the plates was 35.9 \pm 7.22 minutes (ranging from 23-46 minutes). (Table 7) The difference was statistically significant $(\mathrm{P}=0.0001)$. The trapezoidal plate was comparatively more convenient to apply and stabilize.

Both groups showed statistically insignificant difference regarding MMO $(\mathrm{p}=0.340)$, protrusive mandibular movements $(\mathrm{p}=0.180)$, ipsilateral movements $(\mathrm{p}=0.169)$ and contralateral movements $(p=0.419)$. Moreover, the difference between both groups regarding the vertical ramus height ( $\mathrm{p}=0.953)$, anteroposterior condyle angulation $(\mathrm{p}=0.062)$ and mediolateral condyle angulation was statistically insignificant $(\mathrm{p}=0.196),($ Table 7$)$ 
TABLE (4) Change in vertical ramus height in all follow-up periods

\begin{tabular}{|c|c|c|c|c|c|c|c|c|c|c|}
\hline \multirow[t]{2}{*}{$\begin{array}{c}\text { Vertical height of } \\
\text { ramus }\end{array}$} & \multicolumn{4}{|c|}{$\begin{array}{c}\text { Group I } \\
\text { (Single Trapezoidal Plate) }\end{array}$} & \multicolumn{4}{|c|}{$\begin{array}{c}\text { Group II } \\
\text { (Two Mini Plates) }\end{array}$} & \multicolumn{2}{|c|}{ Between groups } \\
\hline & Range & Mean \pm SD & $t$ test & $\begin{array}{c}\mathbf{P}^{@} \\
\text { value }\end{array}$ & Range & Mean \pm SD & $t$ test & $\begin{array}{c}\mathbf{P}^{@} \\
\text { value }\end{array}$ & $t$ value & $\begin{array}{c}\mathbf{P} \\
\text { value }\end{array}$ \\
\hline $\begin{array}{l}\text { VRH of unfractured } \\
\text { condyle }\end{array}$ & $\begin{array}{c}56.3 \\
70\end{array}$ & $64.12 \pm 4.82$ & -- & --- & $\begin{array}{l}57.5 \\
71.3\end{array}$ & $64.75 \pm 5.04$ & -- & --- & .315 & $.756 \mathrm{~ns}$ \\
\hline $\begin{array}{l}\text { Preoperative VRH } \\
\text { of fractured condyle }\end{array}$ & $\begin{array}{c}52.4 \\
64.5 \\
\end{array}$ & $59.60 \pm 4.07$ & 10.38 & $.00^{*}$ & $\begin{array}{c}52.8 \\
67.2 \\
\end{array}$ & $60.13 \pm 5.06$ & 19.53 & $.00 *$ & .285 & $\begin{array}{c}.779 \\
\mathrm{~ns} \\
\end{array}$ \\
\hline $\begin{array}{c}\text { Degree of decrease } \\
\text { in VRH }\end{array}$ & $2.8 ; 8.2$ & $4.55 \pm 1.59$ & --- & --- & $3.8 ; 6.7$ & $4.62 \pm .82$ & --- & --- & .129 & $\begin{array}{c}.899 \\
\text { ns }\end{array}$ \\
\hline 1 week & $\begin{array}{c}55.8 \\
68.7 \\
\end{array}$ & $\begin{array}{c}63.28 \pm 4.77 \\
(0.5-1.3)\end{array}$ & 9.92 & $.00^{*}$ & $\begin{array}{l}56.9 \\
69.7 \\
\end{array}$ & $\begin{array}{c}63.79 \pm 4.90 \\
(0.6-1.6)\end{array}$ & 14.72 & $.00^{*}$ & .258 & $\begin{array}{c}.799 \\
\mathrm{~ns}\end{array}$ \\
\hline 1 month & $\begin{array}{l}55.9 \\
68.5\end{array}$ & $\begin{array}{c}63.54 \pm 4.76 \\
(0.4-1.5)\end{array}$ & -8.26 & $.00^{*}$ & $\begin{array}{l}57.3 \\
69.7\end{array}$ & $\begin{array}{c}63.43 \pm 4.87 \\
(0.2-1.6)\end{array}$ & 0 & $1 \mathrm{~ns}$ & .059 & $\begin{array}{c}.953 \\
\mathrm{~ns}\end{array}$ \\
\hline 3 months & $\begin{array}{l}55.9 \\
68.6 \\
\end{array}$ & $\begin{array}{c}63.54 \pm 4.76 \\
(0.4-1.4) \\
\end{array}$ & 0 & $1 \mathrm{~ns}$ & $\begin{array}{l}57.2 \\
70.2 \\
\end{array}$ & $\begin{array}{c}63.43 \pm 4.87 \\
(0.3-1.1) \\
\end{array}$ & 0 & $1 \mathrm{~ns}$ & .059 & $\begin{array}{c}.953 \\
\mathrm{~ns} \\
\end{array}$ \\
\hline 6 months & $\begin{array}{l}55.9 ; \\
69.2 \\
\end{array}$ & $\begin{array}{c}63.54 \pm 4.76 \\
(0.4-1.0)\end{array}$ & 0 & $1 \mathrm{~ns}$ & $\begin{array}{l}57.3 ; \\
70.5\end{array}$ & $\begin{array}{c}63.43 \pm 4.87 \\
(0.3-0.8)\end{array}$ & 0 & $1 \mathrm{~ns}$ & .059 & $\begin{array}{c}.953 \\
\text { ns }\end{array}$ \\
\hline $\begin{array}{c}\text { Decrease after } 1 \\
\text { week }\end{array}$ & $\begin{array}{c}0.50 \\
1.50\end{array}$ & $0.83 \pm 0.36$ & --- & --- & $\begin{array}{c}0.40 \\
1.70 \\
\end{array}$ & $0.96 \pm 0.46$ & --- & --- & 0.77 & $\begin{array}{c}0.449 \\
\text { ns }\end{array}$ \\
\hline $\begin{array}{c}\text { Decrease after } \\
1 \text { month }\end{array}$ & $\begin{array}{c}0.40 \\
1.50 \\
\end{array}$ & $0.66 \pm 0.42$ & 1.06 & $0.29 \mathrm{~ns}$ & $0.20 ; 6.2$ & $1.33 \pm 1.82$ & 0.683 & $0.509 \mathrm{~ns}$ & 1.24 & $\begin{array}{c}0.227 \\
\text { ns }\end{array}$ \\
\hline
\end{tabular}

Significance level p $\leq 0.05$, *significant $P @$ values for paired t test for comparing 2 subsequent follow-up periods Degree of decrease in VRH (difference between fractured and unfractured condyles)

TABLE (5) Change in Antero-posterior condylar angulation

\begin{tabular}{|c|c|c|c|c|c|c|c|c|c|c|}
\hline \multirow[t]{2}{*}{ A-P angulation } & \multicolumn{4}{|c|}{$\begin{array}{c}\text { Group I } \\
\text { (Single Trapezoidal Plate) }\end{array}$} & \multicolumn{4}{|c|}{ Group II (Two Mini Plates) } & \multicolumn{2}{|c|}{ Between groups } \\
\hline & Range & Mean \pm SD & $\mathrm{t}$ test & $\begin{array}{c}\mathbf{P}^{@} \\
\text { value }\end{array}$ & Range & Mean \pm SD & t test & $\begin{array}{c}\mathbf{P}^{@} \\
\text { value }\end{array}$ & t test & P value \\
\hline $\begin{array}{l}\text { Angulation of } \\
\text { unfractured condyle }\end{array}$ & $\begin{array}{l}5.7 \\
25.3 \\
\end{array}$ & $14.76 \pm 6.41$ & --- & ---- & $10.7 ; 27.7$ & $17.58 \pm 5.87$ & --- & ---- & 1.123 & $\begin{array}{c}.274 \\
\mathrm{~ns}\end{array}$ \\
\hline $\begin{array}{l}\text { Preoperative angulation } \\
\text { of fractured condyle }\end{array}$ & $\begin{array}{l}15.8 \\
37.4\end{array}$ & $25.51 \pm 7.58$ & 17.31 & $.00 *$ & $18.2 ; 37.9$ & $28.32 \pm 6.35$ & 14.82 & $.00^{*}$ & .984 & $.336 \mathrm{~ns}$ \\
\hline Degree of angulation & $\begin{array}{l}6.1 \\
14.9 \\
\end{array}$ & $11.15 \pm 2.45$ & --- & --- & $7.5 ; 16.2$ & $10.74 \pm 2.51$ & --- & ---- & .404 & $\begin{array}{c}.690 \\
\mathrm{~ns}\end{array}$ \\
\hline 1 week & $\begin{array}{l}1.3 \\
4.1\end{array}$ & $2.60 \pm .98$ & 11.31 & $.00^{*}$ & $1.5 ; 5.7$ & $3.38 \pm 1.18$ & 13.87 & $.00^{*}$ & 1.747 & $\begin{array}{c}.095 \\
\mathrm{~ns}\end{array}$ \\
\hline 1 month & $\begin{array}{l}1.1 \\
3.9 \\
\end{array}$ & $2.39 \pm .95$ & 10.79 & $.00 *$ & $1.2 ; 9.3$ & $3.88 \pm 2.37$ & 1.02 & $.33 \mathrm{~ns}$ & 2.03 & $\begin{array}{c}.062 \\
\mathrm{~ns}\end{array}$ \\
\hline 3 months & $\begin{array}{l}1.1 \\
3.9 \\
\end{array}$ & $2.39 \pm .95$ & 0 & $\operatorname{lns}$ & $1.2 ; 9.3$ & $3.90 \pm 2.41$ & 1.00 & $.34 \mathrm{~ns}$ & 2.017 & $\begin{array}{c}.063 \\
\mathrm{~ns}\end{array}$ \\
\hline 6 months & $\begin{array}{l}1.1 \\
3.9\end{array}$ & $2.39 \pm .95$ & 0 & $1 \mathrm{~ns}$ & $1.2 ; 9.1$ & $3.89 \pm 2.39$ & 1.00 & $.34 \mathrm{~ns}$ & 2.022 & $\begin{array}{c}.062 \\
\mathrm{~ns}\end{array}$ \\
\hline
\end{tabular}

Significance level p $\leq 0.05$, *significant P@values for paired t test for comparing 2 subsequent follow-up periods 
TABLE (6) Change in Medio-lateral condylar angulation

\begin{tabular}{|c|c|c|c|c|c|c|c|c|c|c|}
\hline \multirow[t]{2}{*}{ M-L angulation } & \multicolumn{4}{|c|}{$\begin{array}{c}\text { Group I } \\
\text { (Single Trapezoidal Plate) }\end{array}$} & \multicolumn{4}{|c|}{$\begin{array}{c}\text { Group II } \\
\text { (Two Mini Plates) }\end{array}$} & \multicolumn{2}{|c|}{$\begin{array}{l}\text { Between } \\
\text { groups }\end{array}$} \\
\hline & Range & Mean \pm SD & t test & $\begin{array}{c}\mathbf{P}^{@} \\
\text { value }\end{array}$ & Range & Mean \pm SD & t test & $\begin{array}{c}\mathbf{P}^{@} \\
\text { value }\end{array}$ & $t$ test & $\begin{array}{c}P \\
\text { value }\end{array}$ \\
\hline $\begin{array}{c}\text { Angulation of } \\
\text { unfractured condyle }\end{array}$ & $\begin{array}{l}4.2 \\
23.7\end{array}$ & $13.58 \pm 6.36$ & --- & -- & $\begin{array}{l}6.8 \\
24.3\end{array}$ & $15.30 \pm 5.94$ & -- & -- & -.687 & $\begin{array}{c}.499 \\
\mathrm{~ns}\end{array}$ \\
\hline $\begin{array}{l}\text { Preoperative angulation } \\
\text { of fractured condyle }\end{array}$ & $\begin{array}{l}12.3 \\
35.9\end{array}$ & $25.06 \pm 7.61$ & 18.81 & $.00 *$ & $\begin{array}{l}15.5 \\
36.9\end{array}$ & $26.24 \pm 7.38$ & 19.91 & $.00 *$ & -.387 & $\begin{array}{c}.703 \\
\mathrm{~ns}\end{array}$ \\
\hline Degree of angulation & $\begin{array}{l}8.1 \\
14.2\end{array}$ & $11.48 \pm 2.12$ & --- & --- & $\begin{array}{l}7.3 \\
13.9\end{array}$ & $10.94 \pm 1.90$ & -- & --- & .65 & $\begin{array}{c}.517 \\
\mathrm{~ns}\end{array}$ \\
\hline 1 week & $\begin{array}{l}1.4 \\
4.7\end{array}$ & $4.53 \pm .97$ & 10.4 & $.00 *$ & $1.4 ; 5.3$ & $5.73 \pm 1.32$ & 12.05 & $.00 *$ & .406 & $\begin{array}{c}.689 \\
\mathrm{~ns}\end{array}$ \\
\hline 1 month & $\begin{array}{l}1.2 \\
4.5\end{array}$ & $4.15 \pm 6.01$ & 11.00 & $.00 *$ & $1.2 ; 7.6$ & $4.17 \pm 1.84$ & .95 & $.36 \mathrm{~ns}$ & 1.36 & $\begin{array}{c}.191 \\
\mathrm{~ns}\end{array}$ \\
\hline 3 months & $\begin{array}{l}1.2 \\
4.5\end{array}$ & $3.35 \pm .96$ & .00 & $\begin{array}{c}1.00 \\
\mathrm{~ns}\end{array}$ & $1.1 ; 7.3$ & $4.12 \pm 1.79$ & 1.73 & $.11 \mathrm{~ns}$ & 1.31 & $\begin{array}{c}.208 \\
\mathrm{~ns}\end{array}$ \\
\hline 6 months & $\begin{array}{l}1.2 \\
4.5\end{array}$ & $3.34 \pm .97$ & 1.00 & $\begin{array}{l}.34 \\
\mathrm{~ns}\end{array}$ & $1.2 ; 7.4$ & $4.13 \pm 1.79$ & 1.00 & $.34 \mathrm{~ns}$ & 1.35 & $\begin{array}{c}.196 \\
\mathrm{~ns}\end{array}$ \\
\hline
\end{tabular}

Significance level $p \leq 0.05$, *significant, $n s=$ non-significant

$P @$ values for paired t test for comparing 2 subsequent follow-up periods

TABLE (7) Comparison of outcome parameters between the two treatment groups at the end of 6 months

\begin{tabular}{|l|c|c|c|c|}
\hline & $\begin{array}{c}\text { Group I } \\
\text { (Single Trapezoidal Plate) }\end{array}$ & $\begin{array}{c}\text { Group II } \\
\text { (Two Mini Plates) }\end{array}$ & t test & P value \\
\hline Plate fixation time (min) & $17.58 \pm 3.15$ & $35.9 \pm 7.22$ & 8.07 & $0.0001 *$ \\
\hline Occlusal derangement & $0(0 \%)$ & $2(16.6 \%)$ & 2.18 & $0.14 \mathrm{~ns}$ \\
\hline Plate fracture, n (\%) & $0(0 \%)$ & $2(16.6 \%)$ & 2.18 & $0.14 \mathrm{~ns}$ \\
\hline MMO (mm) Mean \pm SD & $42.50 \pm 1.00$ & $41.83 \pm 2.12$ & .983 & $.340 \mathrm{~ns}$ \\
\hline Protrusive movement & $9.88 \pm .56$ & $9.18 \pm 1.64$ & 1.414 & $.180 \mathrm{~ns}$ \\
\hline Ipsilateral movement & $9.93 \pm .62$ & $9.31 \pm 1.35$ & 1.442 & $.169 \mathrm{~ns}$ \\
\hline Contralateral movement & $9.65 \pm 1.25$ & $9.12 \pm 1.86$ & .825 & $.419 \mathrm{~ns}$ \\
\hline Vertical ramus height & $63.54 \pm 4.76$ & $63.43 \pm 4.87$ & .059 & $.953 \mathrm{~ns}$ \\
\hline Anteroposterior condyle angulation & $2.39 \pm .95$ & $3.89 \pm 2.39$ & 2.022 & $.062 \mathrm{~ns}$ \\
\hline Mediolateral condyle angulation & $3.34 \pm .97$ & $4.13 \pm 1.79$ & 1.35 & $.196 \mathrm{~ns}$ \\
\hline Facial nerve weakness & $0(0 \%)$ & $02(16.6 \%)$ & 2.18 & $0.148 \mathrm{~ns}$ \\
\hline Mandibular Mobility Index & $0(0 \%)$ & $02(16.6 \%)$ & 2.386 & $0.303 \mathrm{~ns}$ \\
\hline Helkimo Index of mandibular dysfunction $\mathbf{n}(\boldsymbol{\%})$ & $0(0 \%)$ & $02(16.6 \%)$ & 0.222 & $0.528 \mathrm{~ns}$ \\
\hline
\end{tabular}

SD; standard deviation, TMD; temporomandibular disorder, MMO; maximum mouth opening.

$X^{2}$ or Fisher's exact test for qualitative values and independent $t$ test for quantitative values. 


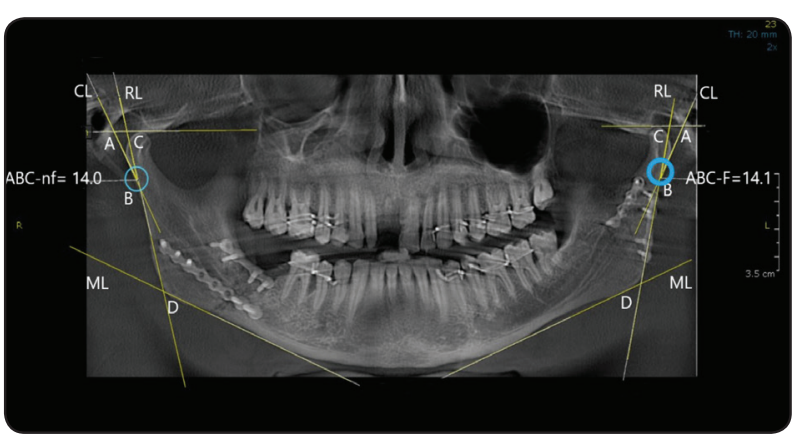

Fig. (10): A photograph of postoperative CBCT reformatted panoramic view showing postoperative measurements of VRH and Antero-posterior condylar angulation of the fractured and un-fractured condyles.

\section{DISCUSSION}

Open reduction and internal rigid fixation of subcondylar fractures favours immediate functional jaw movements through achievement of accurate anatomic reduction of the fractured segments donating better functional, biomechanical and aesthetic outcomes. ${ }^{(7,11-13,19)}$

The present study was conducted to compare clinically and radiographically between the single three-dimensional Trapezoidal plate versus the traditional two non-parallel straight miniplates in the reduction and fixation of unilateral displaced subcondylar fractures.

The trapezoidal plates were effortless and more convenient to adapt and stabilize than the two non-parallel miniplates and thus were superior to the two miniplates group regarding the hardware fixation time. In our study, the median time taken for fixation of the Single Trapezoidal Plate in group I patients was $17.58 \pm 3.15$ minutes (range 12-22 minutes) versus 35.9 \pm 7.22 minutes (range 23-46 minutes) in group II patients which was statistically significant $(\mathrm{P}=0.0001)$.

The traditional two miniplates were sometimes difficult to place in the small proximal condylar segment specially in cases of high subcondylar fractures where optimal anatomical reduction has to be achieved in such fractures to avoid complications

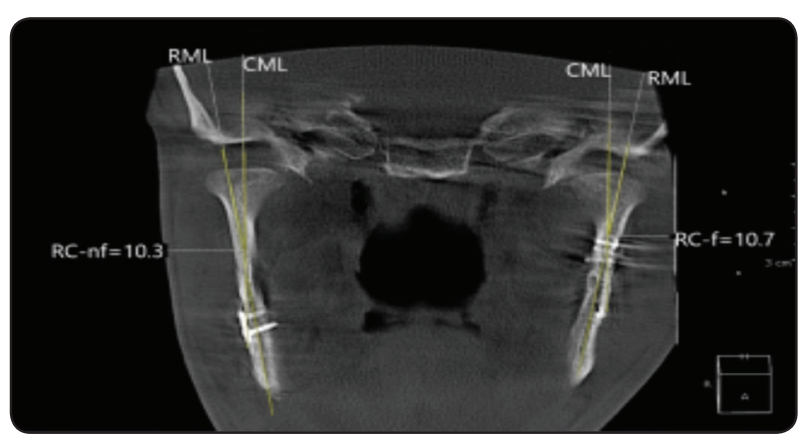

Fig. (11): A photograph of Postoperative CBCT reformatted coronal view showing postoperative measurement of Medio-lateral condylar angulation at the fractured and un-fractured condyles.

of segment deviation upon screw tightening. In contrast, the single Trapezoidal plate, being smaller in profile, permits easy and convenient placement in confined spaces and permits optimal anatomical reduction specially in high subcondylar fractures.

The results of the present study are in agreement with those of various other studies comparing the 3-dimentional miniplate with the conventional two miniplates regarding the ease of adaptation and significantly decreased plate fixation time. ${ }^{(16,18.29,30)}$

The extended plate fixation time and consequently the prolonged operative surgical time had not been considered by many surgeons an issue or matter of great importance. However, a readily valuable and prominent significance of the decreased intraoperative surgical time is the reflected decreased soft tissue retraction time with the resultant benefit of diminished prevalence of facial nerve affection and weakness.

Facial nerve paresis is one of the complications of ORIF of subcondylar fractures. In the present study, all patients were approached through utilizing a modified retromandibular retro-parotid approach. The rationale of this approach is that intra-glandular parotid entry and invasion of its capsule or contents were not required with less evident postoperative scaring and avoidance of complications as salivary fistulae. 
Immediately postoperatively, the facial nerve weakness was not encountered in all patients of group I, while two patients in group II had weakness of the frontal branch of the facial nerve; however, this difference was statistically insignificant $(\mathrm{P}=$ 0.148 ). The nerve weakness was evident on the first post-operative day and had recovered completely by the third postoperative month. At 3 and 6 months, nerve weakness was absent in all cases of both groups.

The reported transient facial nerve affection may be attributed to postsurgical edema and/or the excessive soft tissue retraction applied during reduction, alignment and fixation of the subcondylar fractured segment. Again, the increased hardware fixation time and accordingly the extended period of soft tissue retraction may be a contributing factor for the increased incidence of facial nerve paresis during fixation of the traditional two miniplates system. It has to be noted that even transient facial nerve weakness can integrate and raise a cosmetic burden to patients, leading to dissatisfaction and frustration despite functionally successful results.

The incidence of transient and permanent facial nerve paresis reported in the literature varies from 0 to $14 \%$ and from 0 to $5 \%$ respectively. ${ }^{(13,18,30,31)}$

Two patients (16.6\%) of group II (two miniplates) sustained Plate fracture at the 1-month follow-up interval. These patients exhibited severe mandibular dysfunction and severely impaired mandibular mobility by the end of 6 months despite a 2-3 weeks period of heavy guiding elastics. However, none of the patients registered for a second surgery as they were satisfied from the overall results. In contrast, no patient in group I (trapezoidal plate) had sustained any plate fracture. However, plate fracture in both groups was statistically insignificant $(\mathrm{P}=0.119)$.

Although the statistical difference between both groups was insignificant, this denotes that the two mini-plates were not able to bear and withstand tensile and compression forces at the subcondylar area and accordingly did not provide the desirable rigidity and stabilization. This is especially important in the condylar neck area in cases of high subcondylar fractures where the topography and thickness of bone is usually insufficient to allow insertion of 2 screws per fragment. Trapezoidal plates, on the other hand, through permitting valid and accurate placement of its arms along the ideal osteosynthesis lines of the subcondylar area, can neutralize variable inconstant strains generated along different sites of the reduced condylar segment and sounds to provide the most rigid and stable subcondylar osteosynthesis. So, the design could be functioning as tension and compression plates at the same time with only two vertical screws in proximal segments which could be easily accommodated in small segments and higher-level fractures. ${ }^{(16,18)}$

Haim et al. ${ }^{(32)}$ studied the biomechanics of delta plates in the treatment of subcondylar fractures in 40 porcine mandibles and concluded that delta plates proved to provide the desired rigidity without demonstrating plate fracture.

Similarly, Ahuja et al. in $2018^{(30)}$ in their comparative study made on 20 adult patients requiring ORIF of their subcondylar fractures, analysed the clinical parameters of the two-miniplates in comparison to Delta plates and reported that neither plate fracture nor plate bending had occurred in either of the studied groups. ${ }^{(30)}$ However, various clinical studies had recorded the incidence of plate fracture in the two non-parallel miniplates and the single trapezoidal plate plating systems to range from $0-15 \%$ and $0-1.2 \%$ respectively. ${ }^{(11,17,18)}$

Regarding mandibular movements concerning the MMO, ipsilateral, contralateral and protrusive excursions, were satisfactory in all patients of both groups and were regained gradually throughout the follow-up intervals with no statistically significant differences and gives a great support and similarity to that reported in the available literature. ${ }^{(34-38)}$

In the present study, the Mandibular mobility in- 
dex and the Helkimo index of mandibular dysfunction showed superior results in the trapezoidal plate group compared to the mini-plates group $(\mathrm{P}=0.303$ and $\mathrm{P}=0.528$ respectively) and both groups showed a significant improvement by time. Although the difference between groups was statistically insignificant, these results provide superiority for the single trapezoidal plate regarding the rigidity of fixation and postoperative fracture stability.

Plate fracture that occurred in 2 patients of group II was a reasonable cause for the difference between the 2 groups with respect to mandibular mobility and dysfunction. The available literature had reported the incidence of Temporomandibular disorders TMDs following ORIF of subcondylar fractures to vary from $1 \%$ to $15 \%$. However, this relatively high percentage may be attributed to articular disc injury either secondary to the traumatic event itself or as a sequalae of the surgical procedure with resultant postoperative adhesions and scarring in the TMJ capsular ligament system.

Another possible explanation of these findings may be the fact that conventional miniplates require precise adaptation to the underlying bone to prevent any possible shift or modifications in the alignment of the reduced fractured segments upon screw tightening resulting in more extended gaps and accordingly additional generated torsional forces eventually resulting in changes in occlusal relationship or even plate fracture under loading which had been encountered in two patients of group II ${ }^{(39)}$

The single trapezoidal plating technique accomplishes and executes the principles of functionally stable subcondylar osteosynthesis. Its three-dimensional 4-sided trapezoidal design and because of the extra horizontal bars incorporated in the implant to counteract torquing forces, it provided improved structural rigidity besides functional stability while enabling minimal surgical and soft tissue retraction times. The Functional stability that it offers is primarily achieved by its configuration rather than by plate thickness, length or incorporation of additional number of screws.

In both experimental and clinical studies, shortening of the vertical ramus height of the fractured condyle and the degree of condylar fragment displacement were considered of paramount importance as reference indicators in treating subcondylar fractures. ${ }^{(21)}$

Regarding the VRH, both groups showed statistically significant increase in VRH from preoperatively to 1 -week $(\mathrm{p}=0.00)$ and insignificant increase from 1-week to 1-month with no difference at 3 and 6 months. $(\mathrm{p}=1)$.

The significant postoperative increase in VRH reflects the effectiveness of adequate reduction and stable fixation observed in our study.

In the present study, the average postoperative shortening of the vertical ramus height compared to the unfractured side ranged from 0.4 to 1.5 in group I and from 0.2 to $1.6 \mathrm{~mm}$ in group II. Loukota et al (40) reported that minimal condylar displacement is defined when the postoperative vertical ramus height of the fractured condylar side was less than $2 \mathrm{~mm}$ shorter with respect to the unfractured condylar side and Eckelt et $\boldsymbol{~ a l}^{(41)}$ reported that moderate condylar displacement is defined when the postoperative vertical ramus height of the fractured condylar side was more than $2 \mathrm{~mm}$ shorter than that of the unfractured condylar side.

Loukota et al ${ }^{(40)}$ also reported that minimal condylar displacement is defined when the postoperative angulation of the fractured condyle is less than $10 \circ$, and Eckelt et $\boldsymbol{a l}^{(41)}$ defined moderate condylar displacement as when the postoperative angulation of the fractured condyle is between $10^{\circ}$ and $45^{\circ}$.

In our study, the average degree of postoperative antero-posterior condylar displacement in group I was between 1.1 and 4.1 with a mean of $2.39 \pm .95$, while in group II, the degree of displacement was 
between 1.2 and 9.3 with a mean of $3.89 \pm 2.39$. Group I demonstrated greater decrease in condylar angulation compared to group II although the difference was statistically insignificant.

The average degree of postoperative Mediolateral condylar displacement was less than 4.5 degrees in group I and 7.4 degrees in group II. Group I demonstrated greater decrease in condylar angulation compared to group II although the difference is statistically insignificant. Although the difference between groups was statistically insignificant, these results provide superiority for the single trapezoidal plate regarding the rigidity of fixation and postoperative fracture stability.

Different measurement protocols had been proposed for assessing the vertical ramus height and condylar angulations using different imaging techniques such as computed tomography, magnetic resonance imaging, orthopantomography, and lateral cephalometry. However, all the recorded measurement protocols achieved comparable results to the protocol adopted in the present study as all depend upon recording the same anatomical landmarks. ${ }^{(42)}$

Based on these statistical results, in our study, the attained minimal postoperative shortening of the postoperative ramal height and consequently the minor degree of postoperative condylar segment displacement in both antero-posterior and mediolateral directions reflects not only the efficiency concerning the restoration of adequate mandibular mobility Index and satisfactory TMJ function, but also reflects the stability of fixation monitored in our study. The superiority of the Trapezoidal plates over the conventional 2 miniplates is reflected through the superior results achieved regarding the Helkimo index of mandibular mobility and mandibular dysfunction.

Meyer et al. in $2007^{(16)}$ was the first who introduced and advocated the use of the trapezoidal plates for the purpose of fixation of subcondylar fractures. In their experimental study, the trapezoidal plate yielded satisfactory outcomes regarding its ability to provide adequate rigidity for subcondylar fractures fixation. ${ }^{(16)}$ Trapezoidal plates have also been used successfully in adult populations and proved to provide adequate stable subcondylar fracture fixation. ${ }^{(11,17,18)}$

More recently, Albogha et al in $2018^{(20)}$ analysed Patient-specific finite element models to compare the biomechanical performance of 5 designs of 3-dimensional titanium miniplates (lambda, strut, delta, rhombic and trapezoid) for the rigid fixation of subcondylar fractures and concluded that the trapezoid miniplate was superior concerning biomechanical performance since it offered the greatest rigidity and stability while counteracting and neutralizing variable types of strains.

Comparable results had been achieved by

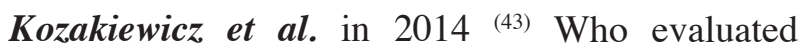
A-shaped plates, another type of three-dimensional plate, and postulated the efficiency of these plates in rigid fixation of high condylar neck and coronoid process fractures and stated that these plates could be used for all levels of condylar fractures. ${ }^{(43)}$

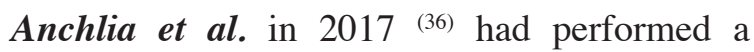
comparative clinical study to evaluate lambda plates versus delta plates using modified miniretromandibular sub-parotid approach, and the results found no difference between the two plating designs, but the approach was more conservative, tissue sparing, and with less complications.

The results of our study give a great support to those of a recent study done in 2018, by Mahmoud F.et al, ${ }^{(37)}$ who evaluated the efficiency of application of the 3D Rhombic plates in the fixation of displaced low subcondylar fractures and concluded that the 3D Rhombic plates were compatible for treatment of condylar fractures and provided satisfactory stable fixation.

Ashor et al, ${ }^{(38)}$ in 2018 in their prospective randomized controlled clinical trial compared the outcomes of the $3 \mathrm{D}$ rhombic plates with the 2.0 miniplates in management of subcondylar fractures. 
They concluded that the three-dimensional rhombus plates had clinical and radiographic outcomes comparable to the two miniplates, offering less operative time, with strong recommendation for high subcondylar fractures which is in agreement to the results of our study.

Bhowmick et al ${ }^{(44)}$ in 2019 compared five plating systems including two 4 hole double mini plate, Delta plate, inverted Y mini plate, Trapezoidal plate and Lambda plate and measured the anteroposterior width of the condylar neck on CT scans of 10 hemimandibles of healthy individuals and concluded that a single Trapezoidal plate fulfilled the criteria of functionally stable osteosynthesis on the condylar neck and provided greater functional and biomechanical stability due to its shape and configuration. They reported that the large surface area between the two plate arms and the minimal periosteal stripping required and the maximum preservation of proximal blood supply resulted in better healing.

The results of our study are in accordance with those of Adhikari et al ${ }^{(28)}$ in 2020 who compared in a randomized clinical trial one trapezoidal plate with two miniplates in treating subcondylar fractures in 52 patients and concluded that both systems provided functionally stable fixation with comparable clinical outcomes in the two groups regarding MMO and mandibular excursions. They reported the seniority of the single trapezoidal plating system over the traditional 2 miniplates plating system regarding the time taken for plate insertion and easiness of adaptation.

The limitations or probable weakness of the present study is that patients with associated mandibular fractures had been registered in the study which can confound and confuse the results because the fixation requisites of a double fracture generally conflict from an isolated fracture. However, this was attributed to the very low incidence of isolated subcondylar fractures as fracture of this unique area of the mandible is frequently caused by indirect forces delivered or conveyed to the subcondylar area from abroad forces that usually is not fully absorbed in the majority of cases in the area of its initial application resulting in associated parasymphyseal, body or angle fractures.

In conclusion, both the single trapezoidal plate and the two non-parallel miniplates provided functionally stable osteosynthesis regarding subcondylar fracture fixation. The single trapezoidal plate proved its seniority over the traditional two miniplates concerning the time taken for plate insertion and fixation. The trapezoidal plates were more convenient to apply and stabilize. The complications of plate fracture and transient facial nerve paresis had been encountered in two patients of the two miniplates group but had not been encountered in patients of the trapezoidal plate group. The VRH, antero-posterior and mediolateral condylar angulations were superior in the trapezoidal plate group although this was statistically insignificant. Mandibular mobility and Helkimo index of TMJ dysfunction were superior in the trapezoidal plate group although this was statistically insignificant. The occlusion, mouth opening, lateral and protrusive excursions outcomes were similar without any statistical difference between both groups. Based upon the findings of this study, the single trapezoidal plate should be prioritized over the two non-parallel straight miniplates regarding ORIF of subcondylar fractures.

\section{CONCLUSION}

Both the single trapezoidal plate and the two non-parallel miniplates fixation systems provided functionally stable osteosynthesis in subcondylar fractures. The trapezoidal plate proved its seniority over the two miniplates regarding the time taken for plate insertion, adaptation and stabilization but comparable to the two miniplates regarding the other clinical parameters.

Based upon the results of the present study, we recommend and support the use of single Trapezoidal 
plates in ORIF of displaced subcondylar fractures with special recommendation for high subcondylar fractures for their small profile enabling fixation in the confined space of the small proximal condylar segment while eliminating the need for extended soft tissue retraction time and accordingly reducing the incidence of facial nerve paresis.

\section{REFERENCES}

1. Chrcanovic BR. Factors influencing the incidence of maxillofacial fractures. Oral Maxillofac Surg. 2012; 16(1): 3-17. doi: 10.1007/s10006-011-0280-y. PMID: 21656125.

2. Chrcanovic BR, Abreu MH, Freire-Maia B, Souza LN. Facial fractures in children and adolescents: a retrospective study of 3 years in a hospital in Belo Horizonte, Brazil. Dent Traumatol. 2010; 26(3): 262-70. doi: 10.1111/j.16009657.2010.00887. x. PMID: 20456472.

3. Chrcanovic BR, Souza LN, Freire-Maia B, Abreu MH. Facial fractures in the elderly: a retrospective study in a hospital in Belo Horizonte, Brazil. J Trauma. 2010; 69(6): 738. doi: 10.1097/TA.0b013e3181cc847b. PMID: 20693928.

4. Chrcanovic BR, Abreu MH, Freire-Maia B, Souza LN. 1,454 mandibular fractures: a 3-year study in a hospital in Belo Horizonte, Brazil. J Craniomaxillofac Surg. 2012; 40(2): 116-23. doi: 10.1016/j.jcms.2011.03.012. PMID: 21458284.

5. Zandi M, Khayati A, Lamei A, Zarei H. Maxillofacial injuries in western Iran: a prospective study. Oral Maxillofac Surg. 2011; 15(4): 201-9. doi: 10.1007/s10006-011-02776. PMID: 21660436.

6. Hackenberg B, Lee C, Caterson EJ. Management of subcondylar mandible fractures in the adult patient. J Craniomaxillofac Surg. 2014; 25(1): 166-71. doi: 10.1097/ SCS.0000000000000498. PMID: 24406572.

7. Al-Moraissi EA, Ellis E, Surgical Treatment of Adult Mandibular Condylar Fractures Provides Better Outcomes than Closed Treatment: A Systematic Review and Meta-Analysis, Journal of Oral and Maxillofacial Surgery (2014), doi: 10.1016/j.joms.2014.09.027.

8. Kokemueller H, Konstantinovic VS, Barth El, Goldhahn S, Von See C, Tavasso F, Essig H, Gellrich NC. Endoscopeassisted transoral reduction and internal fixation versus closed treatment of mandibular condylar process fractures-a prospective double- center study. J Oral Maxillofac Surg 2012; 70: 384-395.
9. Choi K-Y, Yang J-D, Chung H-Y, Cho B-C. Current concepts in the mandibular condyle fracture management part II: open reduction versus closed reduction. Arch Plast Surg 2012; 39:301-308.

10. Fayazi S, Bayat M, Bayat-Movahed S, Sadr-Eshkevari P, Rashad A. Long-term outcome assessment of closed treatment of mandibular fractures. J Craniofac Surg. 2013; 24(3): 735-9. doi: 10.1097/SCS.0b013e3182801373. PMID: 23714869.

11. Zrounba H, Lutz JC, Zink S, Wilk A (2014) Epidemiology and treatment outcome of surgically treated mandibular condyle fractures. A five years retrospective study. J Craniomaxillofac Surg 42:879-884. doi: 10.1016/j. jems.2014.01.002

12. Akdag O, Yildiran G, Abaci M, Tosun Z. EndoscopicAssisted Treatment Combined with Transoral and Transbuccal Approach to Mandibular Subcondylar Fractures. Journal of Oral and Maxillofacial Surgery. 2017 Dec 5:15.

13. Rozeboom AV, Dubois L, Bos RR, Spijker R, de Lange J. Open treatment of condylar fractures via extraoral approaches: a review of complications. Journal of CranioMaxillofacial Surgery. 2018 May 18

14. Kisnisci R. Management of fractures of the condyle, condylar neck, and coronoid pro-cess. Oral Maxillofac Surg Clin North Am 2013; 25:573-90.

15. Choi BH, Yi CK, Yoo JH. Clinical evaluation of 3 types of plate osteosynthesis for fixation of condylar neck fractures. J Oral Maxillofac Surg 2001; 59:734-7.

16. Meyer C, Martin E, Kahn JL, Zink S. Development and biomechanical testing of a new osteosynthesis plate (TCP) designed to stabilize mandibular condyle fractures. J Craniomaxillofac Surg 2007; 35:84-90.

17. Chaudhary M, Pant H, Singh M, Vashistha A, Kaur G. Evaluation of trapezoidal-shaped 3-D plates for internal fixation of mandibular subcondylar fractures in adults. J Oral Biol Craniofac Res 2015; 5:134-9.

18. Meyer C, Zink S, Chatelain B, Wilk A. Clinical experience with osteosynthesis of subcondylar fractures of the mandible using TCP plates. J Craniomaxillofac Surg 2008; 36:260-8.

19. Darwich MA, Albogha MH, Abdelmajeed A, Darwich K. Assessment of the bio-mechanical performance of 5 plating techniques in fixation of mandibular subcondylar fracture using finite element analysis. J Oral Maxillofac Surg 2016;74(794). e1-794.e8. 
20. Albogha MH, Mori Y, Takahashi I. Three-dimensional titanium miniplates for fixation of subcondylar mandibular fractures: comparison of five designs using patient-specific finite element analysis. J Craniomaxillofac Surg 2018; 46:391-7.

21. Veras RB, Kriwalsky MS, Eckert AW, et al. Long-term outcomes after treatment of condylar fracture by intraoral access: a functional and radiologic assessment. J Oral Maxillofac Surg2007; 65:1470-6.

22. Quan XY, Qin M, Kang YF, et al. Radiographic and masticatory physiologic evaluation after conservative treatment of condylar fractures in children and adolescents. Zhonghua Kou Qiang Yi Xue ZaZhi 2016; 51:30-5 (paper in Chinese).

23. Helkimo M. Studies on function and dysfunction of the masticatory system. 3 . Analyses of anamnestic and clinical recordings of dysfunction with the aid of indices. Svensk tandlakare tidskrift. Swedish dental journal. 1974 May; 67(3):16581-.

24. Gribel BF, Gribel MN, Frazäo DC, McNamara JA Jr, Manzi FR (2011) Accuracy and reliability of craniometric measurements on lateral cephalometry and 3D measurements on CBCT scans. Angle Orthod 81(1):26-35.

25. Swasty D, Lee J, Huang JC, Maki K, Gansky SA, Hatcher D, Miller AJ (2011) Cross-sectional human mandibular morphology as assessed in vivo by cone-beam computed tomography in patients with different vertical facial dimensions. Am J Orthod Dentofac Orthop 139(4): e377389. https ://doi.org/10.1016/j.ajodo .2009.10.039

26. Changa S. P, Yangb Y, Shic L.Q, Liua Y.W, Liua Y, Ma Q. Modification of the measurement of the major variables in mandibular condylar fractures: angulation of sidewards displacement and shortening of the height of the ramus. British Journal of Oral and Maxillofacial Surgery xxx (2017) xxx-xxx YBJOM-5316; No. of Pages 7

27. Silvennoinen U, Iizuka T, Oikarinen K, Lindqvist C. Analysis of possible factors leading to problems after nonsurgical treatment of condylar fractures. Journal of oral and maxillofacial surgery. 1994 Aug 31; 52(8):7939-.

28. Neff A, Cornelius CP, Rasse M, et al. The comprehensive AOCMF classification system: condylar process fractures-level 3 tutorial. Craniomaxillofac Trauma Reconstr 2014; 7(Suppl.1): SO44-58.

29. M. Adhikari, K. Bhatt, R. Yadav, J. Mandal, O. Bhutia, A. Roychoudhury: Fixation of subcondylar fractures of the mandible: a randomized clinical trial comparing one trap- ezoidal plate with two miniplates. Int. J. Oral Maxillofac. Oct 2020; xxx: xxx- xxx. YIJOM-4567; No of Pages 7

30. Ahuja SA, Galinde J, Asnani U, Mistry YA. Comparative evaluation of clinical outcomes using delta plates and conventional mini-plates for internal fixation of mandibular condylar fractures in adults. J Oral Maxillo-fac Surg 2018; 76:1255-66.

31. Al-Moraissi EA, Louvrier A, Colletti G, Wolford LM, Biglioli F, Ragaey M, et al. Does the surgical approach for treating mandibular condylar fractures affect the rate of seventh cranial nerve injuries? A systematic review and meta-analysis based on a new classification for surgical approaches. J Craniomaxillofac Surg 2018; 46:398-412.

32. Haim D, Mu“ller A, Leonhardt H, Nowak A, Richter G, Lauer G. Biomechanical study of the Delta plate and the Tri-Lock Delta condyle trauma plate. J Oral Maxillofac Surg 2011; 69:2619-25.

33. Vesnaver A, Ah9can U, Rozman J. Evaluation of surgical treatment in mandibular condyle fractures. J Craniomaxillofac Surg 2012; 40:647-53.

34. Danda AK, Muthusekhar MR, Narayanan V, Baig MF, Siddareddi A. Open versus closed treatment of unilateral subcondylar and condylar neck fractures: a prospective, randomized clinical study. J Oral Maxillofac Surg 2010; 68:1238-41.

35. Singh G, Mohammad S, Das S, Passi D, Vishwakarma K. Trapezoidal condylar plate: report of 15 cases in the management of mandibular subcondylar fracture. J Adv Med Dent Sci 2013; 1:13-18.

36. Anchlia S, Parmar R, Nagwadia V, Dhuvad J, Shah J, Domadia H. Twodimensional lambda versus three-dimensional delta plates in subcondylar fracture using modified mini retromandibular subparotid approach. Int J Oral Maxillofac Surg 2017; 46:256.

37. Mahmoud F. Abu Eldahab, Mohammad M. Shoushan, Mohammad A. Elshall, Ibrahim M. Nowair. Evaluation of Rhombic Three-Dimensional Plate in Fixation of Displaced Low Subcondylar Mandibular Fractures. Oral and maxillofacial surgery journal May 2018 Vol 9 issue 3 pages $126-134$.

38. Mohamed H. Ashor, Ahmed M. Salah, Mustafa I. Shindy, Heba A.E. Selim, Salah A.E. Metwaly and Galal G.E. Behairy. Clinical and radiographic outcomes of rhomboid plate in management of subcondylar fractures: prospective randomized controlled trial. The Egyptian Association of Oral \& Maxillofacial Surgeons. 2018, Vol. 09 No. 1 
39. HAUG RH, STREET CC, GOLTZ M. Does Plate Adaptation Affect Stability? A Biomechanical Comparison of Locking and Nonlocking Plates. J Oral Maxillofac Surg 2002; 60: 1319-1326.

40. Loukota RA, Eckelt U, De Bont L, et al. Subclassification of fractures of the condylar process of the mandible. Br J Oral MaxillofacSurg2005; 43:72-3.

41. Eckelt U, Schneider M, Erasmus F, et al. Open versus closed treatment of fractures of the mandibular condylar process-a prospective randomized multi-centre study. J Craniomaxillofac Surg2006; 34:306-14.
42. Markic G, Müller L, Patcas R et al (2015) Assessing the length of the mandibular ramus and the condylar process: a comparison of OPG, CBCT, CT, MRI, and lateral cephalometric measurements. Eur J Orthod 37(1):13-21 I, February 2015.

43. Kozakiewicz M, Swiniarski J. 'A' shape plate for open rigid internal fixation of mandible condyle neck fracture. $\mathrm{J}$ Craniomaxillofacial Surg 2014; 42:730-737.

44. Bhowmick R S, Bhowal K and Samiran Ghosh S. Plating systems for 3D stability of subcondylar fracture: A research article with review of literature. International Journal of Orthopaedics Sciences 2019; 5(2): 681-683 